\title{
Intelligence and Visual Mismatch Negativity: Is Pre-Attentive Visual Discrimination Related to General Cognitive Ability?
}

\author{
Kirsten Hilger ${ }^{1,2, *}$, Matthew J. Euler ${ }^{3}$, \\ ${ }^{1}$ Goethe University, Department of Neurocognitive Psychology, Frankfurt am Main, Germany \\ ${ }^{2}$ Justus Maximilian University Würzburg, Department of Psychology I, Würzburg, Germany \\ ${ }^{3}$ University of Utah, Department of Psychology, Salt Lake City, Utah, USA
}

Kirsten Hilger (D) https://orcid.org/0000-0003-3940-5884

Matt Euler (D) https://orcid.org/0000-0002-9741-049X

*Corresponding author:

Dr. Kirsten Hilger

University of Würzburg

Marcusstr. 9-11

97070 Würzburg

Germany

kirsten.hilger@uni-wuerzburg.de 


\title{
INTELLIGENCE AND VISUAL MISMATCH NEGATIVITY
}

\begin{abstract}
Intelligence captures the cognitive ability level of an individual person and electroencephalography (EEG) has been used for decades to identify neurocognitive processes related to intelligence. The mismatch negativity (MMN) is a component of the event-related brain potential (ERP) that is elicited when, within a series of frequent standard stimuli, rare deviant stimuli are presented. As stimuli are typically presented outside the focus of attention, the MMN is suggested to capture automatic pre-attentive discrimination processes, and mixed results have been reported in relation to intelligence. However, the MMN and its relation to intelligence has only been studied in the auditory domain, thus preventing any conclusion about the involvement of automatic discrimination processes in humans dominant sensory modality, i.e., vision. Here we provide a first test of this question. Electroencephalography was recorded from 50 healthy participants during a passive visual oddball task that presented simple sequence violations as well as deviations within a more complex hidden pattern. Signed area amplitudes and fractional area latencies of the visual mismatch negativity (vMMN) were calculated with and without Laplacian transformation. Neither vMMN amplitudes nor vMMN latencies were significantly related to intelligence (Ravens Advanced Progressive Matrices, RAPM) and Bayes Factors suggest moderate evidence for the absence of associations. Our study presents the first test of whether neural indices of pre-attentive visual discrimination processes are related to intelligence. We discuss critical differences between the auditory and visual MMN and conclude with a discussion of limitations and recommendations for further research in this evolving field.
\end{abstract}


bioRxiv preprint doi: https://doi.org/101101/2022 03 01.482097; this version posted March 3, 2022. The copyright holder for this preprint (which was not certified by peer review) is the author/funder, who has granted bioRxiv a license to display the preprint in perpetuity. It is made available under aCC-BY-ND 4.0 International license.

\section{INTELLIGENCE AND VISUAL MISMATCH NEGATIVITY}

\section{HIGHLIGHTS}

- Testing whether intelligence is related to automatic visual discrimination

- Visual mismatch negativity (vMMN) as a neural indicator of pre-attentive processing

- Passive visual oddball task presents simple and complex rule violations

- No association between intelligence and vMMN amplitudes or latencies

- Fundamental differences between auditory and visual MMN?

\section{KEYWORDS}

- Cognitive Ability

- Mismatch Negativity (MMN)

- Automatic Sensory Discrimination

- Pre-Attentive Processing

- EEG/ERP 


\section{INTELLIGENCE AND VISUAL MISMATCH NEGATIVITY}

\section{Introduction}

Intelligence is a psychological construct that includes the ability to understand complex ideas, to adapt effectively to the environment, to learn from experience, and to engage in various forms of reasoning (Neisser et al., 1996). Various tests have been developed that allow the calculation of so called intelligence quotients. Respective scores try to capture the general cognitive ability level of a person and have been shown to predict educational and occupational success (Schmidt \& Hunter, 2004) as well as positive life outcomes such as health and longevity (Deary et al., 2004). Understanding the cognitive processes contributing to different levels of intelligence is therefore an important aim of ongoing research across multiple scientific disciplines.

The study of individual variation in neural parameters assessed during specific tasks (involving specific cognitive processes) provides a means to gain insight into the question of how certain processes may contribute to individual differences in intelligence. Neuroimaging research has identified neural correlates of intelligence in brain structure (e.g., Haier et al., 2004; Hilger et al., 2020a), brain function (e.g., Gray et al., 2003; Lipp et al., 2012), and in intrinsic brain connectivity (e.g., Hilger et al., 2020b; for general reviews on neuroimaging correlates of intelligence see Basten et al. 2015; Hilger \& Sporns, 2021; Jung and Haier 2007). However, such research often provides only limited insights into intelligence-critical processes, as the identified neural parameters that covary with differences in intelligence (e.g., intrinsic connectivity in region of the dorsal attention network, DAN) were typically not assessed during an intelligencecritical cognitive processes. Rather they were assessed during the resting state (brain morphology, intrinsic connectivity) or during tasks not necessarily related to intelligence (e.g., movie watching; Haier et al., 2003). Although findings from previous investigations allow for vague interpretations about the meaning of these identified intelligence-related parameters (e.g., other studies that showed that regions of the DAN were associated with attentional processes), any such inferences are rather speculative, especially because most neural parameters have been associated not only with one but with many different processes (reverse inference problem, Nathan \& Del Pinal, 2017; Poldrack, 2008, 2011, 2015).

The study of event-related brain potentials (ERP) with electroencephalographic recordings during a specific task allows to more directly study the relation between variability in intelligence and its association with process parameters. Beyond the P3 (i.e., the third positive deflection to a specific consciously detected stimulus; Luck, 2014), the auditory mismatchnegativity $(\mathrm{MMN})$ has evolved as promising marker of individual differences of intelligence (e.g., De Pascalis et al., 2014; De Pascalis \& Varriale, 2012; Houlihan \& Stelmack, 2012; Sculthorpe et al., 2009; Troche et al., 2009, 2010). In general, the MMN is elicited when, within a series of frequent standard stimuli, rare deviant stimuli are presented (e.g., tones of higher pitch). As stimuli are typically presented outside the focus of attention, the MMN is suggested to capture automatic pre-attentive discrimination processes (Näätänen et al., 2007). Associations between higher intelligence and larger (i.e., more negative) MMN amplitudes have been observed in multiple studies (De Pascalis et al., 2014; De Pascalis \& Varriale, 2012; Houlihan \& Stelmack, 2012; Sculthorpe et al., 2009; Troche et al., 2009, 2010) as well as a relation between higher intelligence and shorter MMN latencies (De Pascalis et al., 2014; De Pascalis \& Varriale, 2012; Sculthorpe et al., 2009). However, associations were mostly of moderate effect size $(\sim r=-.15$ to $r=-.42$ ) and different studies also failed to find respective relations (e.g., Bauchamp \& 

available under aCC-BY-ND 4.0 International license.

\section{INTELLIGENCE AND VISUAL MISMATCH NEGATIVITY}

Stelmack, 2006; De Pascalis \& Varriale, 2012; Troche et al., 2010), suggesting a more heterogeneous picture.

Although vision constitutes humans' dominant sensory modality (e.g., Hutmacher, 2019), automatic discrimination processes via the MMN have typically been investigated in the auditory domain only. The development of experimental paradigms that allow to assess the MMN also in the visual domain have started recently. Respective studies suggest that violations in simple and also more complex visual patterns that are presented outside the focus of attention elicit an electrophysiological component similar to the auditory MMN, i.e., the visual MMN (vMMN; e.g., Stefanics et al., 2011, 2014; for review see Pazo-Alvarez et al., 2003). One pioneering study tested also for an association between vMMN and intelligence (Liu et al., 2015). However, this study investigated an emotional vMMN elicited by rather complex perceptual stimuli (facial expressions), which may be hard to set in relation to findings from auditory MMN research where the MMN is typically elicited by rather unemotional and overall simple perceptual discrimination processes. Whether variations in the vMMN indexing simple visual discrimination processes relate to individual differences in intelligence therefore still constitutes an open question.

Here, we address this gap and transfer an established experimental vMMN paradigm (Stefanics et al., 2011) to research in the field of intelligence. We present different ways to compute the vMMN as elicited by simple and more complex rule violations and use state-of-the-art operationalizations of its amplitude and latency. To preview our results, we observed a clear vMMN, replicating previous work. However, neither its amplitude nor its latency was related to variation in intelligence, and Bayes Factors were consistent with the absence of an association. We conclude with a discussion of limitations and recommendations for further research in this evolving field.

\section{Method}

\section{Participants and Assessment of Intelligence}

60 right-handed students from Goethe University Frankfurt completed the experiment for monetary compensation or student credits. The size of this sample was determined by an a priori power calculation in combination with monetary feasibility. Specifically, based on previous work on the auditory MMN and intelligence (e.g., Sculthorpe et al., 2009), we expected an effect size $\sim .35$, which resulted, when ensuring $80 \%$ statistical power, in a required sample size of $N>$ 49 participants (G*Power, Faul et al., 2007; two-tailed, $\alpha=.05$ ). As we expected that some participants need to be excluded, we collected data of 60 persons. Students with a Major or Minor study subject in Psychology were excluded. All participants had self-reported normal or corrected-to-normal visual acuity and no history of psychiatric or neurological diseases. The procedures were approved by the local ethics committee (\# 2015-201) and informed written consent according to the Declaration of Helsinki was obtained from all participants. Seven participants completed an earlier version of the protocol and were excluded due to insufficient numbers of trials. One additional participant was excluded due to EEG acquisition failure, and two participants were excluded due to an insufficient number of useable trials after artifact correction (i.e., fewer than $n=40$ artifact-free trials in any single condition), leaving a final 


\section{INTELLIGENCE AND VISUAL MISMATCH NEGATIVITY}

sample of $N=50$ subjects (13 men, 37 women). Demographic information for the final study sample is listed in Table 1. Intelligence was assessed in group settings (10-12 participants) with Raven's Advanced Progressive Matrices (RAPM, Raven et al., 1998). The RAPM sum scores were used in all analyses as the primary variable of interest and varied in the final sample between 12 and $34(M=24.56, S D=4.74$; Table 1) corresponding to an IQ score between 65 and $123(M=92.32, S D=.14 .97)$.

Table 1

Descriptive statistics for individual difference variables

\begin{tabular}{llll} 
& $M(S D)$ & Minimum & Maximum \\
\hline Age & $26.64(3.62)$ & 18 & 33 \\
RAPM & $24.56(4.74)$ & 12 & 34 \\
Reaction Time & $0.53(0.04)$ & 0.23 & 0.66 \\
Accuracy & $0.97(0.07)$ & 0.53 & 1.0 \\
\hline
\end{tabular}

Note: $N=50$ (13 men, 37 women). Reaction Time (in seconds) and Accuracy reflect overall values averaged across all task blocks. RAPM = Ravens Advanced Progressive Matrices sum score.

\section{Stimuli and Procedure}

The paradigm used in the present study was adapted from Stefanics et al. (2011). The task was presented on a Windows computer and the distance between participant and screen (21.5 inch diagonal) was $120 \mathrm{~cm}$. Experimental stimuli consisted of 24 red or green circles (diameter 2.5 $\mathrm{cm}$; vertical distance between centers of stimuli: $4.5 \mathrm{~cm}$; horizontal distance between centers of stimuli: $4 \mathrm{~cm}$; total area covered by colored discs: $20 \times 25 \mathrm{~cm}$ ) and were shown for $100 \mathrm{~ms}$ on a computer screen with black background (see Fig. 1). All stimuli were presented pairwise, defined by shorter (within-pair; $300 \mathrm{~ms}$ ) and longer (between-pair; $800 \mathrm{~ms}$ ) inter stimulus intervals (ISIs; full trial duration $1,300 \mathrm{~ms})$.

To study discrimination processes outside the focus of attention (passive oddball task), the participants were instructed to focus exclusively on a white fixation cross in the center of the screen and to index any perceived change of the cross (target) by a speeded button press. At irregularly-spaced time points either both horizontal arms of the cross or both vertical arms became a little bit longer (50\% of changes in the fixation cross refer to vertical arms, 50\% to horizontal arms; vertical arms changed from 1 to $1.25 \mathrm{~cm}$; horizontal arms changed from 1.25 to $1.5 \mathrm{~cm}$ ). On average, targets (cross change) were presented 10 times per minute. Furthermore, targets were matched and consequently equally distributed across deviant and standard trials as well as across red and green stimuli. The correct detection of a target as indexed by a button press within $800 \mathrm{~ms}$ after target onset was defined as hit, no reaction within $800 \mathrm{~ms}$ was registered as miss, and all other responses counted as false alarms.

The experiment consisted of three different conditions (see Fig. 1). In the first oddball condition (simple/red) red stimuli served as standards and green stimuli served as deviants and were presented with a ratio of $80 \%$ to $20 \%$, respectively. A reverse oddball condition had identical parameters, with the exception that green stimuli served as standards and red stimuli served as deviants (simple/green). This allowed us to compare physically identical stimuli as standards vs. 
bioRxiv preprint doi: https://doi.org/10.1101/2022.03.01.482097; this version posted March 3, 2022. The copyright holder for this preprint (which was not certified by peer review) is the author/funder, who has granted bioRxiv a license to display the preprint in perpetuity. It is made available under aCC-BY-ND 4.0 International license.

\section{INTELLIGENCE AND VISUAL MISMATCH NEGATIVITY}

deviants, thereby controlling for neural adaptation processes resulting from different physical stimulus features. The order of red and green stimuli within each block was pseudo-randomized to ensure that each block began with at least four standard stimuli. Further, two deviants were not allowed to be presented directly after each other, but could occur at the first or the second position within a stimulus pair. In Figure 1, this is shown for simple/green, but not for simple/red. In respect to the attention control task, we ensured that a cross change could happen only once per stimulus pair (either at the first or second stimulus).

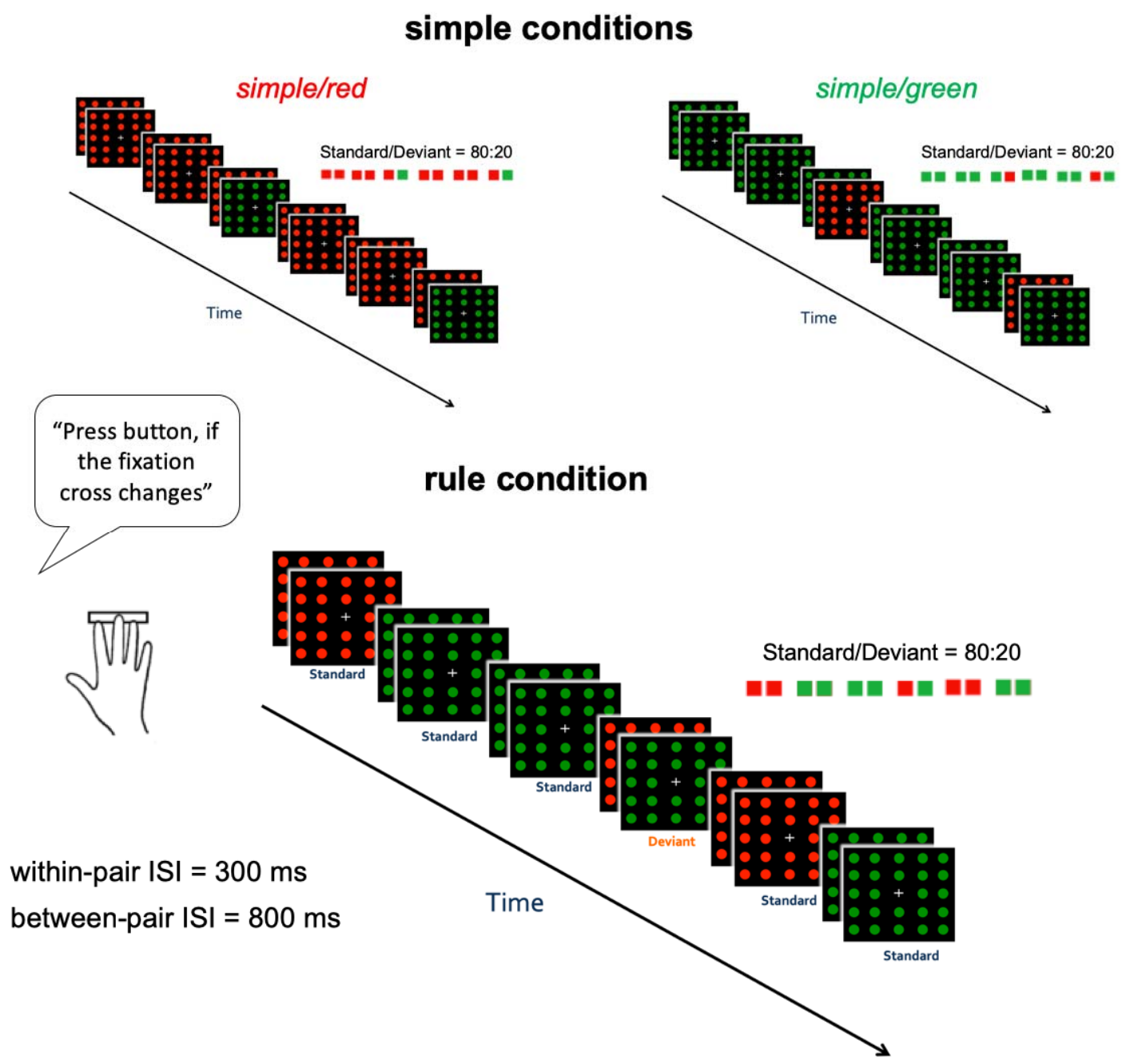

Fig. 1. Schematic illustration of the passive oddball task. Top: Simple conditions (simple/red and simple/green). Bottom: Rule condition (rule). Stimuli were presented pairwise each for $100 \mathrm{~ms}$ with an ISI of $300 \mathrm{~ms}$ between two stimuli of the same pair and an ISI of $800 \mathrm{~ms}$ between two stimuli of different pairs (total trial duration: $1300 \mathrm{~ms}$ ). Participants were instructed to focus on the fixation cross and to indicate via button press when they detect slight changes in the arm lengths of the fixation cross (occurring without any regularity on average 10 times per minute). Each block comprised 100 trials (100 pairs, 200 stimuli). The whole experiment consisted of 12 blocks, i.e., four blocks of each condition. 


\section{INTELLIGENCE AND VISUAL MISMATCH NEGATIVITY}

Finally, a more abstract, rule-based oddball task (rule) was implemented, where a standard was defined as a pair of two same-colored stimuli (red-red or green-green). The deviant in this condition was a stimulus pair with two different colors, which was presented in $20 \%$ of trials. As the decision about whether a stimulus pair represents a deviant or not, always requires knowledge about the color of the second stimulus within a pair, deviance is in this condition always defined (and the corresponding neural mismatch response is initiated) by the occurrence of the second stimulus (see also Fig. 1). The probability of red and green stimuli was equal within the whole block and the order of stimuli was pseudo-randomized such that at least four standard stimulus pairs were presented at the beginning of each block. Two deviant-pairs were not allowed to be presented after each other and cross changes could happen only once within a pair and not in two consecutively presented stimulus pairs. In the following, the first two oddball conditions (simple/red and simple/green) are labeled as 'simple' conditions, whereas the last condition is labeled as 'rule'.

A total of 12 blocks was presented, with 4 blocks for each condition. For each subject, the order in which the 12 different pseudo-randomized stimulus blocks (see above) were presented within the whole experiment, was generated purely by chance (completely randomized). Each block comprised 100 trials (i.e., 100 pairs, 200 stimuli) and took two minutes and 16 seconds. At the end of each block, the participants could decide to make a short break and were instructed to start the new block on their own when they felt ready.

\section{EEG Recording and Preprocessing}

EEG data were recorded with 64 active $\mathrm{Ag} / \mathrm{AgCl}$ electrodes (arranged in an extended 10-20 layout), using actiChamp amplifier (Brain Products GmbH, Gilching, Germany), FCz was the online reference electrode, and AFz served as the ground. The sampling rate was $1,000 \mathrm{~Hz}$, impedance levels were kept below $10 \mathrm{kOm}$, and a low pass filter of $280 \mathrm{~Hz}$ was applied during acquisition (notch filter off). Two electrodes were placed below the left (SO1) and the right (SO2) eye to record ocular artifacts, and mastoid electrodes were placed behind both ears (M1, M2). Preprocessing and further analyses of EEG data were conducted in EEGLAB (Delorme \& Makeig, 2004) and ERPLAB (Lopez-Calderon \& Luck, 2014), and followed established standards for ERP processing and analysis (https://erpinfo.org/order-of-steps; Luck, 2014).

First, the continuous data were loaded into EEGLAB and a high-pass filter at $0.1 \mathrm{~Hz}$ was applied to correct any low-frequency drift. Data segments corresponding to task breaks were removed (time segments of $\geq 2000 \mathrm{~ms}$ or longer where no event code/trigger occurred, with $500 \mathrm{~ms}$ buffer around the immediately preceding and following event code). The data were re-referenced to the average of all scalp electrodes, and two virtual bipolar EOG electrodes were created (consisting of Fp1 and SO1, Fp2 and SO2) to facilitate the identification of blink-related artifacts. The data were then epoched from -100 to $400 \mathrm{~ms}$ relative to stimulus onset, for each stimulus within a pair, and each epoch was linearly-detrended. This produced twelve sets of data epochs corresponding to the following sub-conditions: standard red and deviant green stimuli in first vs. second position from the simple/red condition (4 epoch types), standard green and deviant red stimuli in first vs. second stimulus position from the simple/green condition (4 epoch types), and standard or deviant red and green stimuli from the rule condition (4 epoch types; all time-locked to the second stimulus in a pair as deviance vs. standard is in the rule condition always defined by the occurrence of the second stimulus of a pair, see above and Fig. 1). To avoid any possible 

available under aCC-BY-ND 4.0 International license.

\section{INTELLIGENCE AND VISUAL MISMATCH NEGATIVITY}

confounding of the ERP effects due to motor preparation, all stimuli presented during an interval of $800 \mathrm{~ms}$ after a fixation cross change were excluded from ERP analyses. For the same reason, we excluded all trials in which a button was pressed although not required (false alarm).

The epoched data were then used to identify 'bad' electrodes, i.e., electrodes for which more than $4 \%$ of trials would have been rejected due to non-blink-related artifacts, such as drift, or high-frequency noise by the automatic EEGLAB artifact-rejection procedure (voltage changes $\geq$ $60 \mu \mathrm{V}$ on either side of a $100 \mathrm{~ms}$ window across $50 \mathrm{~ms}$ steps or voltage differences exceeding $100 \mu \mathrm{V}$ within a $100 \mathrm{~ms}$ window, moving in $50 \mathrm{~ms}$ steps). The continuous (non-epoched) data of these electrodes were then manually reviewed and replaced via spherical-spline interpolation. Of note, our strict interpolation strategy resulted in, on average, 8.76 interpolated electrodes per subject $(S D=6.71$; range: $0-26)$. However, we selected this very conservative artifact rejection approach to gain a very clean grand-average picture unaffected by idiosyncratic bad electrodes across participants. Importantly, of the nine electrodes used for statistical analyses (see below), only few have actually been interpolated $(M=0.54$ per subject; $S D=.97$; range: $0-3)$ suggesting minimal influences of our strict interpolation strategy on the vMMN estimation.

Thereafter, the same automated threshold-based routines were applied to now identify artifactual epochs containing either step-like artifacts in the ocular channels (those with voltage changes $\geq$ $60 \mu \mathrm{V}$ on either side of a $100 \mathrm{~ms}$ window across $50 \mathrm{~ms}$ steps), or with voltage differences exceeding $100 \mu \mathrm{V}$ within a $100 \mathrm{~ms}$ window, moving in $50 \mathrm{~ms}$ steps, across any scalp channels. All final data files were then manually reviewed again to ensure appropriate inclusion and exclusion of valid and artifactual trials by these algorithms. After rejecting trials contaminated due to artifacts, $77 \%$ of the total possible trials were retained for calculating ERP calculation (average, across all participants and conditions). No participant had fewer than $43 \%$ of the total possible trials retained (minimum absolute number $=14 / 32$ trials for the deviant rule conditions), with up to $100 \%$ of trials being retained in many participants and conditions. The average percentage of trials retained across participants in each of the twelve sub-conditions ranged from $73 \%-82 \%$.

\section{Event-Related Potentials}

For the primary analyses, the cleaned epochs were then baseline-corrected relative to the $100 \mathrm{~ms}$ preceding the stimulus, and event-related potentials (ERPs) were created by averaging all epochs within each of the 12 epoch types. The resulting averaged ERPs were low-pass filtered at $10 \mathrm{~Hz}$, to minimize high-frequency noise that can contaminate ERP latency measurements (Luck, 2014). Note that the analyses of within-subject condition effects focus on these epoch type-averaged ERPs (i.e., trial-averaged ERPs for each of the 12 epochs; where our aim is to establish the presence of a vMMN and its sensitivity to condition effects). In contrast, the individual differences analyses focus on ERP difference waves, which were derived by subtracting the ERP elicited by standard stimuli from the ERP elicited by deviant stimuli. For the simple task conditions, these difference ERPs were calculated based on standard and deviant stimuli with the same color and from the same position in the stimulus pair ( $1^{\text {st }}$ vs. $2^{\text {nd }}$ stimulus), resulting in a 'red/ 1 st, difference ERPs (i.e., red deviants minus red standards from the first position in the stimulus pairs), as well as 'red $/ 2^{\text {nd, }}$, 'green $/ 1^{\text {st, }}$, and 'green $/ 2^{\text {nd, }}$ difference ERPs. In the rule condition, we calculated one difference ERP for red deviants relative to red standards and one difference ERP for green deviants relative to green standards (all of which calculated from the 
bioRxiv preprint doi: https://doi.org/10.1101/2022.03.01.482097; this version posted March 3, 2022. The copyright holder for this preprint available under aCC-BY-ND 4.0 International license.

\section{INTELLIGENCE AND VISUAL MISMATCH NEGATIVITY}

respective second stimuli in a pair). This process resulted in a total of six ERP difference waves that served as basis to identify the vMMNs.

\section{ERP Measurement Strategy}

For each subject-specific trial-averaged ERP and the ERP difference wave (vMMN), we used ERPLAB algorithms to calculate the signed integral area amplitudes and the $50 \%$ fractional area latencies (Luck, 2014) in the period from 100-400 ms post-stimulus, at the nine posterior electrodes (P3, Pz, P4, PO3, POz, PO4, O1, Oz, O2) where vMMN effects were previously observed by Stefanics and colleagues (2011) in a similar paradigm. Because the vMMN is defined as a relative negativity, the amplitude results reported below reflect the area of the negative deflections subtracted from any positive values, and similarly, fractional area latencies were calculated for negative deflections only.

To further clarify the optimal measurement parameters of these effects, and particularly in regards to their sensitivity towards individual differences, we additionally conducted a parallel analysis approach. Here, we first applied the surface Laplacian transform via the CSD toolbox (Kayser \& Tenke, 2006; http://psychophysiology.cpmc.columbia.edu/Software/CSDtoolbox/) to the data and calculated amplitude and latency measurements afterwards. The Laplacian transform provides a reference-free estimate of the activity at the dura at each electrode, which is suggested to improve the spatial specificity of the obtained ERP effects (Kayser \& Tenke, 2015). In the following (and in all Figures/Tables) we will refer to the former approach (described above) as 'Scalp-Average Referenced' and to the latter as 'Laplacian-Transformed'.

Amplitudes and latency values were then averaged over all participants and conditions to obtain a sample-specific grand-average difference wave, as a basis to reliably identify the time-window in which vMMN occurs in our sample. As depicted in Fig. 2 (lower panels), there is a clear negative maximum at electrodes $\mathrm{POz}$ and $\mathrm{Oz}$ between 125 and $275 \mathrm{~ms}$ post-stimulus, which was therefore defined as the time-window of interest for the calculation of signed area amplitudes and $50 \%$ fractional area latencies in the parallel analysis approach based on the Laplaciantransformed data.

Last, given prior research indicating a relationship between intelligence and neural variability (Euler et al., 2015; Hilger et al., 2020a), we also sought to explore potential effects of trial-totrial amplitude variation, as a post-hoc analysis, on the average-referenced data only. To this end, we calculated the standard error of the mean (SEM) across the cleaned, unfiltered trials for each of the twelve epoch types. These analyses focused on the twelve epoch types (sub-conditions) by necessity, because calculating the SEM requires single trial data and thus cannot be obtained from the epoch type-specific average ERPs or their resulting difference waves. As above, we focused on the integral of the SEM, from 100-400 ms post-stimulus, relative to the $100 \mathrm{~ms}$ prestimulus baseline, in the nine electrodes of a priori interest.

\section{Data Analyses}

Primary data analyses were conducted in SPSS version 25. We performed two sets of analyses with the goal of (1) verifying whether the experimental manipulation was successful in eliciting a vMMN in all conditions (i.e., simple and rule), and (2) assessing whether vMMN amplitudes or latencies correlate with individual differences in intelligence. 
bioRxiv preprint doi: https://doi.org/10.1101/2022.03.01.482097; this version posted March 3, 2022. The copyright holder for this preprint (which was not certified by peer review) is the author/funder, who has granted bioRxiv a license to display the preprint in perpetuity. It is made available under aCC-BY-ND 4.0 International license.

\section{INTELLIGENCE AND VISUAL MISMATCH NEGATIVITY}

\section{Effects of Stimulus Condition}

For the first set of analyses we sought to replicate Stefanics et al. (2011) as closely as possible. Hence, following their approach, we collapsed over red and green stimuli and conducted two repeated-measures ANOVAs, with four factors (Stimulus Deviance: standard vs. deviant; Stimulus Position: first vs. second; Anteriority: parietal, parieto-occipital, occipital; and Hemisphere: left, midline, right; factorial design: $2 \times 2 \times 3 \times 3$ ) to examine the effects of experimental manipulations on ERP amplitudes and latencies. For the rule condition, all ERPs had been calculated on $2^{\text {nd }}$ -

\section{Scalp-Average Referenced}
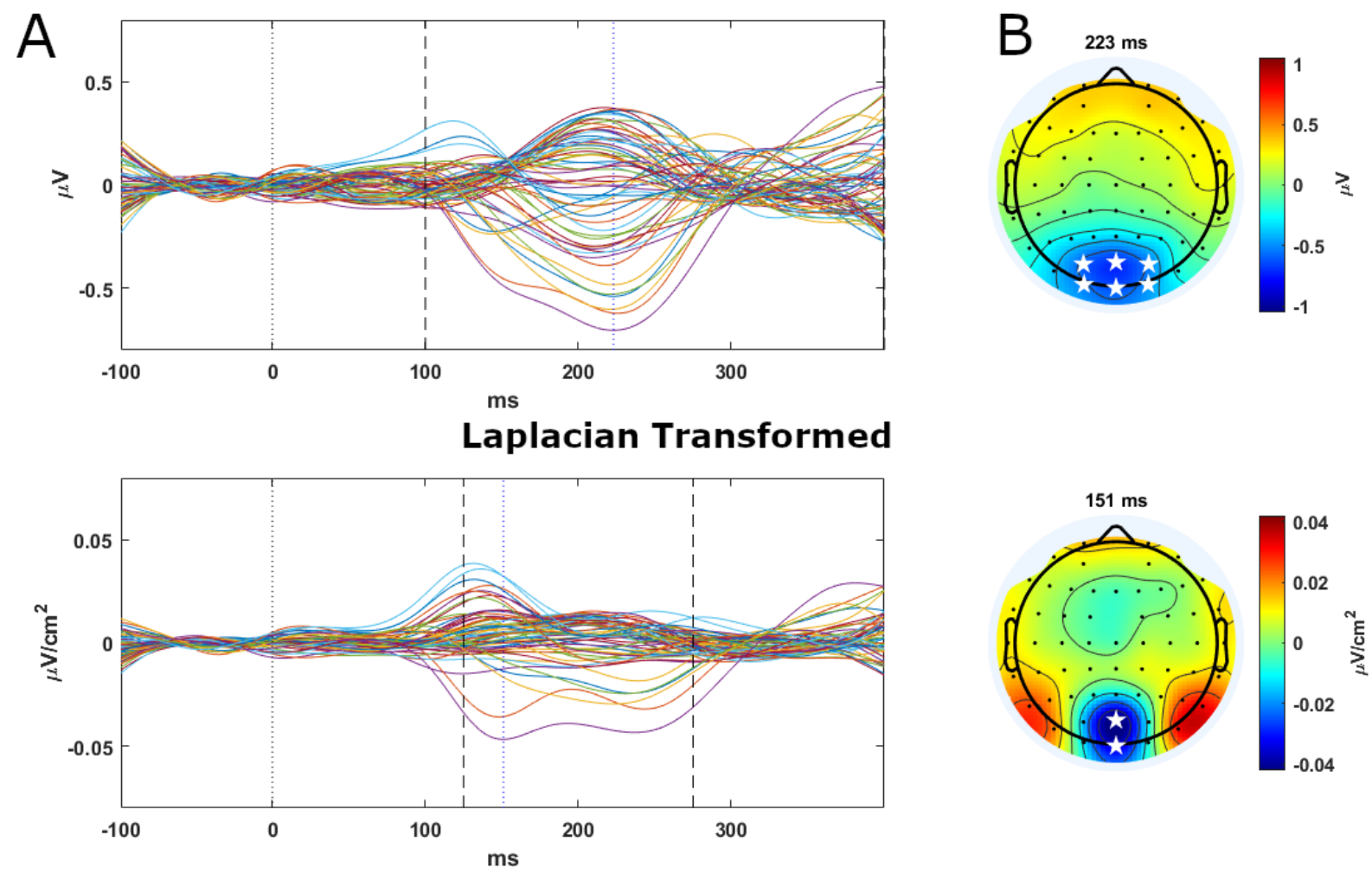

Fig. 2. Group-averaged ERP difference waves (MMNs) for scalp-averaged-referenced and Laplacian-transformed data. Top: Group-averaged, scalp average-referenced differences waves and peak activity, over all participants and conditions. Bottom: analogous plots for the Laplacian-transformed data. A, Different channels are illustrated in different (randomly selected) colors. Dashed black lines indicate measurement windows for each measurement approach, blue dotted lines indicate peak ERP difference waves (vMMN) latencies depicted in the scalp maps at right. B, Scalp maps. Stars highlight the electrodes where the vMMN effects became most visible in our sample and did thus serve as bases for all individual-difference analysis (see Methods section for further details). Note that units and measurement scales differ: scalp- referenced data are in $\mu \mathrm{V}$ and Laplacian-transformed data are in $\mu \mathrm{V} / \mathrm{cm}^{2}$.

position stimuli (see above), resulting in $2 \times 3 \times 3$ ANOVAs (Deviance $\mathrm{x}$ Hemisphere $\mathrm{x}$ Anteriority) for both amplitudes and latencies. The Greenhouse-Geisser correction was applied for all tests containing three or more factors (Luck, 2014), and the Bonferroni correction was applied to control for multiple comparisons when resolving main effects. Of note, we observed 
bioRxiv preprint doi: https://doi.org/10.1101/2022.03.01.482097; this version posted March 3, 2022. The copyright holder for this preprint available under aCC-BY-ND 4.0 International license.

\section{INTELLIGENCE AND VISUAL MISMATCH NEGATIVITY}

that in small number of instances the trial-averaged ERP (within-subject analyses) or difference wave (individual difference analyses) was exclusively within the positive range in the respective time-window of interest. In these cases, the integral area amplitude takes a positive value, but the fractional area latency measure was not defined at all. Thus, the analyses of within-subjects effects (ANOVAs) included all $N=50$ participants in respect to vMMN amplitudes, while within-subjects analyses conducted on latency measures relied on only $N=48$ participants in the basic condition and on $N=47$ participants in the rule condition after excluding those with positive difference waves.

\section{Individual Difference Analysis}

For individual difference analyses, we maintained the distinction between red and green stimuli and examined partial correlations (corrected for age and sex) between RAPM scores and amplitudes/latency measures of each of the six ERP difference waves (vMMNs). To reduce the number of statistical comparisons, we decided a priori to average over activity at the same nine electrodes as included in the within-subject analyses. As noted above, we implemented also a second analysis strategy to gain an additional, reference-free estimate of neural activity with higher spatial specificity, i.e., based on the Laplacian transformed data. Also here, we calculated partial correlations with RAPM scores based on these current source density estimates (averaged across electrodes $\mathrm{POz}$ and $\mathrm{Oz}$ ) controlling for effects of age and sex. Thus, for each of the two analysis approaches (and the corresponding time-electrode-window schemes), we obtained one amplitude and one latency measures from each of the six ERP difference waves for the individual difference (correlation) analyses (red and green in $1^{\text {st }}$ and $2^{\text {nd }}$ position for the simple conditions, and red and green for rule). When applying Bonferroni correction also in respect to the six experimental conditions, the corrected $p$-value would be .008 . Tables 3 and 4 list uncorrected $p$-values.

A final methodological consideration concerns the individual difference analyses of the ERP latencies. As the calculation of the 50\%-fractional area latency measure resulted in missing values in some cases (see above), the respective latency measures could not simply be averaged across electrodes (as it has been done for the amplitude measure; see Schafer \& Graham, 2002). Thus, we conducted 'multiple imputation', which is well-established principled method for dealing with missing data (Graham, 2009). In brief, the process involves replacing each missing value with a simulated value, which is obtained via a random draw from a predicted distribution of the respective variable (for details see Schafer \& Graham, 2002). This process is performed multiple times, resulting in a set of complete datasets each containing simulated copies of the missing values. Of note, these datasets were generated in a ways that the distributional properties of the variable were preserved. Each imputed dataset is then analyzed with conventional statistics (here partial correlations between RAPM score and latency value controlling for age and sex), and the resulting parameter estimates (partial correlations, $r$ ) are pooled arithmetically over all imputed datasets (Sinharay et al, 2001). Following the guidelines reported in Sinharay et al. (2001), we generated five imputed datasets. As the pooled (averaged across all imputed data sets) partial correlation coefficients were aggregated through Fisher-Z-transform, we could not report conventional $p$-values in these cases. 

available under aCC-BY-ND 4.0 International license.

\section{INTELLIGENCE AND VISUAL MISMATCH NEGATIVITY}

To quantify the evidence also in favor of the null hypothesis (i.e., absence of an association between intelligence and ERP difference waves measures) Bayes Factors $\left(\mathrm{BF}_{01}\right.$, Jeffreys, 1998; Wagenmakers, 2007; Wetzels \& Wagenmakers, 2012) and 95\% credibility intervals (CIs) were calculated for all associations of primary interest (associations between intelligence and ERP difference waves measures). We used the Bayesian test for correlated pairs (Jeffreys, 1961) and the default prior (stretched beta distribution of width 1, also termed Jeffrey prior) as implemented in JASP version 0.11.1 (Love et al., 2015). To approximate pooled partial correlations (controlled for age and sex), we based this analyses on residual intelligence scores, i.e., any variance due to age and sex was regressed from RAPM sum scores prior to computation of Bayesian correlations.

\section{Data and Code Availability}

All analysis code used in the current study has been deposited on GitHub at https://github.com/KirstenHilger/IQ_Coding. The raw study data can be accessed from the authors upon request.

\section{Results}

Descriptive statistics for reaction times, accuracies, and RAPM performance are listed in Table 1. Participants were highly accurate in performing the target detection task $(M=97 \%$ correct; $S D=$ $0.07)$, and the sample mean was near the $50^{\text {th }}$ percentile for RAPM performance relative to German norms for ages 25-29 (Raven \& Court, 1998). Descriptive statistics for ERP amplitudes and latencies are presented in Table 2. In terms of numerical effects (i.e., prior to conducting inferential statistics), examination of the relevant means in the simple conditions suggest that amplitudes were larger (more negative-going) and latencies were faster in response to secondposition stimuli relative to first-position stimuli, and in response to deviant stimuli relative to standard stimuli. No clear differences were evident for amplitudes or latencies in the rule condition.

Table 2

Descriptive statistics for group-averaged ERP amplitudes and latencies

\begin{tabular}{|c|c|c|c|}
\hline \multicolumn{4}{|l|}{ Amplitudes } \\
\hline & $M(S D)$ & Minimum & Maximum \\
\hline \multicolumn{4}{|l|}{ simple } \\
\hline Standard, $1^{\text {st }}$ position & $-0.07(.39)$ & -1.21 & 0.67 \\
\hline Standard, $2^{\text {nd }}$ position & $-0.49(.47)$ & -1.97 & 0.22 \\
\hline Deviant, $1^{\text {st }}$ position & $-0.16(.44)$ & -1.47 & 0.58 \\
\hline Deviant, $2^{\text {nd }}$ position & $-0.61(.50)$ & -2.14 & 0.17 \\
\hline \multicolumn{4}{|l|}{ rule } \\
\hline Standard, $2^{\text {nd }}$ position & $-0.52(.49)$ & -2.08 & 0.27 \\
\hline Deviant, $2^{\text {nd }}$ position & $-0.53(.51)$ & -2.13 & 0.27 \\
\hline \multicolumn{4}{|l|}{ Latencies } \\
\hline & $M(S D)$ & Minimum & Maximum \\
\hline \multicolumn{4}{|l|}{ simplet } \\
\hline Standard, $1^{\text {st }}$ position & $272.00(94.68)$ & 154.5 & 380.0 \\
\hline Standard, $2^{\text {nd }}$ position & $216.17(78.89)$ & 142.0 & 378.0 \\
\hline Deviant, $1^{\text {st }}$ position & $257.03(93.75)$ & 152.0 & 378.0 \\
\hline Deviant, $2^{\text {nd }}$ position & $204.21(65.81)$ & 144.5 & 371.0 \\
\hline \multirow{2}{*}{\multicolumn{4}{|c|}{ rule $\ddagger$}} \\
\hline & 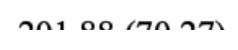 & $\ln n$ & $\operatorname{sen} n$ \\
\hline
\end{tabular}




\section{INTELLIGENCE AND VISUAL MISMATCH NEGATIVITY}

Note: Amplitude and latency values are reported for electrode POz. Amplitudes reflect the integral of the waveform from $100-400 \mathrm{~ms}$, in $\mu \mathrm{V}^{*} \mathrm{~ms}$, where negative voltages have been subtracted from positive voltages. Latencies are in milliseconds. Simple = values averaged across red/green stimuli in both simple conditions. Rule = rule condition. $N$ $=50$ subjects were used for the calculation of amplitude measures, $\dagger N=48$ for latency measures in the simple condition, and $\ddagger N=47$ for latency measures in the rule condition. See Methods section for further details.

Third, the interactions of Deviance and Hemisphere and Deviance and Anteriority (see Supplementary Table S1) indicate that, consistent with the key assumption of MMN research, deviant stimuli elicited larger ERP amplitudes than standards at all levels of Hemisphere (all $p$ values $>.001$ ) and at all levels of Anteriority (all $p$-values $>.001$ ). When the effects of stimulus Deviance were considered with respect to their spatial dimensions, they also suggest a maximum near POz (Supplementary Fig. S2). Specifically, amplitudes were consistently larger at the midline than in the left or right hemisphere for both deviant and standard stimuli (all $p$-values $<.001$ ), while amplitudes over left and right hemispheres did not differ from each other (all $p$ values $\geq .639$ ); and likewise, deviant stimuli elicited greater amplitudes at parieto-occipital than either parietal $(p=.041)$ or occipital sites $(p=.016)$, which did not themselves differ from each other $(p>$.999). This difference was not observed for standard stimuli, however, where amplitudes were larger at $\mathrm{POz}$ than $\mathrm{Oz}(p=.010)$, but not $\mathrm{Pz}(p=.327)$, and similarly, $\mathrm{Pz}$ and $\mathrm{Oz}$ did not differ from one another $(p=.999)$. For the sake of interest, Supplementary Table S1 contains a full statistical analysis of all possible interactions.

\section{ERP Amplitudes - Rule Condition}

In the rule condition, we examined the effects of stimulus Deviance, Hemisphere, and Anteriority, and their respective interactions. Only the main effects of Anteriority $(F(1.285$, $62.985)=7.608, p=.004$, partial $\left.\eta^{2}=.134\right)$, Hemisphere $(F(1.576,77.217)=38.754, p<.001$, partial $\left.\eta^{2}=.442\right)$, and their interaction reached statistical significance $(F(2.997,146.872)=6.861$, $p<.001$, partial $\eta^{2}=.123$ ). Thus, the experimental manipulation in the rule condition did not elicit a clear vMMN, i.e., there was no significant difference in group-averaged amplitudes between deviant and standard stimuli $\left(F(1,49)=.232, p=.632\right.$, partial $\left.\eta^{2}=.005\right)$. Also here (similarly as with the pooled simple stimuli, see above), the significant interaction reflected the spatial specificity of the ERPs, such that amplitudes were largest near POz (moving both right to left and anterior to posterior), with particularly pronounced differences between $\mathrm{POz}$ (midline) and PO3/PO4 (left/right) and relative to analogous contrasts at parietal or occipital sites. Supplementary Table S2 lists the full range of statistics.

In summary, ERP amplitude results for the simple conditions were consistent with previous research indicating larger ERPs in response to deviant versus standard stimuli, and following the second versus the first stimuli of a pair. Although stimulus Position and Deviance did not interact, they showed similar spatial effects, with each being most pronounced near the midline parietooccipital electrode POz. In contrast to a previous study using the same paradigm (Stefanics et al., 
bioRxiv preprint doi: https://doi.org/10.1101/2022.03.01.482097; this version posted March 3, 2022. The copyright holder for this preprint available under aCC-BY-ND 4.0 International license.

\section{INTELLIGENCE AND VISUAL MISMATCH NEGATIVITY}

2011), in our sample the rule condition deviant stimuli did not elicited larger amplitudes than standard stimuli.

\section{ERP Latencies - Simple Conditions}

In the four-way ANOVA examining the effects of Stimulus Position, Deviance, Anteriority, and Hemisphere on ERP latencies, the main effects of Position $(F(1,47)=67.577, p<.001$, partial $\left.\eta^{2}=.590\right)$, Deviance $\left(F(1,47)=16.443, p<.001\right.$, partial $\left.\eta^{2}=.259\right)$, and Hemisphere $(F(1.668$, $78.375)=12.693, p<.001$, partial $\left.\eta^{2}=.213\right)$ reached statistical significance, as well as the twoway interactions of Position and Deviance $\left(F(1,47)=6.515, p=.014\right.$, partial $\left.\eta^{2}=.122\right)$, Position and Hemisphere $\left(F(1.903,89.432)=5.429, p=.007\right.$, partial $\left.\eta^{2}=.104\right)$, and Anteriority by Hemisphere $\left(F(2.749,129.195)=3.853, p=.013\right.$, partial $\left.\eta^{2}=.076\right)$. All three- and four-way interactions were not significant (see also Supplementary Table S3).

More detailed simple main effect tests on the latencies indicated first that ERP latencies were consistently earlier for second- vs. first-position stimuli (all $p<.001$ ). This pattern was found across all two-way interactions such that the various interactions moderated this effect. Second, as indicated by the interaction of Position by Hemisphere, latencies were consistently earlier at midline relative to left or right hemisphere electrodes (all $p \leq .05$ ), which did not differ from each other (all $p>.999$ ); though this effect was greater for first relative to second-position stimuli. Last, in respect to the interaction between Hemisphere and Anteriority, we observed that latencies were shorter at midline relative to right and left hemisphere sites (all $p \leq .013$ ), that right and left sites did not differ from each other (all $p>$.999), and that this difference was especially pronounced between midline and right parietal and parieto-occipital sites (see Supplementary Fig. S3). A full list of statistics is presented in Supplementary Table S3.

\section{ERP Latencies - Rule Condition}

Finally, in the ANOVA examining the effects of Deviance, Anteriority, and Hemisphere on latencies in the rule condition, only the main effect of Hemisphere $(F(1.667,76.693)=6.664, p$ $=.004$, partial $\left.\eta^{2}=.127\right)$, and the three-way interaction were significant $(F(3.507,161.332)=$ $2.997, p=.025$, partial $\left.\eta^{2}=.061\right)$. The full list of statistics is presented in Supplementary Table S4.

In summary, analyses of ERP latencies from the simple conditions indicated that, consistent with previous research, latencies tended to be faster to deviant than to standard stimuli, to secondrelative to first position stimuli, and to midline relative to peripheral electrodes. The latter became most visible at parieto-occipital sites i.e., especially at POz (see Supplementary Fig. S4). In contrast to previous research using the same paradigm (Stefanics et all., 2011), in our sample the rule condition latencies were not faster to deviant than to standard stimuli.

\section{Individual Differences Analyses}

\section{Visual Mismatch Negativity and Individual Differences in Intelligence}

In respect to our main question of interest, i.e., whether intelligence is associated with neural indicators of simple visual discrimination processes (i.e., the vMMN), we observed no significant associations between vMMN amplitudes and the RAPM scores, neither in the scalpreferenced data, nor in the Laplacian-transformed data (Table 3). As nearly all Bayes Factors 


\section{INTELLIGENCE AND VISUAL MISMATCH NEGATIVITY}

$\left(\mathrm{BF}_{01}\right)$ were $>3$ (only $\mathrm{BF}_{01}$ for rule red $\mathrm{MMN}$ was 2.55 ), our results provide substantial evidence for the null hypothesis, i.e., absence of association between intelligence and MMN amplitudes (interpretation of $\mathrm{BF}$ in accordance with Jeffreys, 1961). As an example, the $\mathrm{BF}_{01}$ of 5.57 for the association between intelligence and the vMMN amplitude for red first-position stimuli (Table 3) indicates that the null hypothesis is $\sim 6$ times more likely than the alternative hypothesis (i.e., presence of a correlation). Also, all $95 \%$ credibility intervals included zero, which further supports the absence of any association. For the sake of completeness, partial correlations between vMMN amplitudes of different conditions are provided in Supplementary Table S5.

Table 3

Partial correlations, Bayes Factors, and 95\% credibility intervals for associations between intelligence and vMMN amplitudes

\section{Scalp-Referenced}

\begin{tabular}{|c|c|c|c|c|c|c|}
\hline Statistic & $\mathrm{red} / 1^{\mathrm{st}}$ & green $/ 1^{\text {st }}$ & $\mathrm{red} / 2^{\mathrm{nd}}$ & green $/ 2^{\text {nd }}$ & rule red & rule green \\
\hline Partial $r$ & 0.03 & -0.15 & 0.11 & 0.00 & 0.19 & -0.16 \\
\hline$B F_{01}$ & 5.57 & 3.48 & 4.41 & 5.67 & 2.55 & 3.21 \\
\hline$C I$ & {$[-.25, .30]$} & {$[-.40, .14]$} & {$[-.18, .36]$} & {$[-.27, .27]$} & {$[-.10, .43]$} & {$[-.41, .13]$} \\
\hline
\end{tabular}

\section{Laplacian-Transformed}

\begin{tabular}{lllllll}
\hline Partial $r$ & -0.12 & 0.10 & 0.08 & -0.01 & 0.11 & -0.16 \\
$B F_{01}$ & 4.18 & 4.47 & 4.94 & 5.67 & 4.36 & 3.22 \\
$C I$ & {$[-.37, .17]$} & {$[-.18, .36]$} & {$[-.20, .34]$} & {$[-.28, .26]$} & {$[-.17, .36]$} & {$[-.41, .13]$} \\
\hline
\end{tabular}

Note: Partial $r=$ pooled partial correlation coefficients controlling for variance due to age and sex. Red $/ 1^{\text {st }}=\mathrm{ERP}$ difference wave calculated from red deviants minus red standards from the first position in the stimulus pairs, $\mathrm{red} / 2^{\text {nd }}$, green $/ 1^{\text {st }}$, and green $/ 2^{\text {nd }}$ respectively. Correlations that reach significance in the imputed datasets are marked with an asterisk $\left(*=p<.05\right.$; uncorrected for six experimental conditions). Bayes Factors $\left(\mathrm{BF}_{01}\right)$ in favor of the null hypothesis (i.e., absence of correlation) and 95\% credibility Intervals (CI) are depicted for associations with RAPM scores.

With respect to the latencies, there emerged one single significant correlation, i.e., between intelligence and the vMMN elicited by green stimuli in the rule condition $(r(46)=-.29, p \leq .046$, across five imputed datasets. However, significance only holds when not correcting for multiple tests, i.e., for more than one experimental condition, see Table 4). No other significant association was observed. Also here, most Bayes Factors were $>3$, and all credibility intervals included zero. Even in the above-mentioned case, in which the $p$-value indicated statistical significance (rule green $\mathrm{MMN}$ ), the $\mathrm{BF}_{01}$ of 1.98 demonstrates that the null hypothesis (absence of an association) is about two times more likely than the alternative hypothesis (presence of an association) and the $95 \%$ credibility interval included zero. Partial correlations between vMMN latencies of different conditions are provided in Supplementary Table S6.

To gain more comprehensive insights into the processes eliciting the vMMN, we also tested for potential associations between vMMN amplitudes/latencies and reaction times. We found no 
bioRxiv preprint doi: https://doi.org/10.1101/2022.03.01.482097; this version posted March 3, 2022. The copyright holder for this preprint (which was not certified by peer review) is the author/funder, who has granted bioRxiv a license to display the preprint in perpetuity. It is made available under aCC-BY-ND 4.0 International license.

\section{INTELLIGENCE AND VISUAL MISMATCH NEGATIVITY}

significant associations for the amplitudes neither for the scalp-average-referenced nor the Laplacian-transformed data. For the latencies, only one single significant relation emerged, i.e., between RTs and red stimuli in the first position of the simple conditions in the scalp-referenced data $(r(46)=.32, p=.025$, in each of the five imputed sets, uncorrected for multiple experimental conditions). However, as no other associations between vMMN latencies and RT were observed, most of the data does not support an association between RTs and vMMNs. Respective statistics are listed in Supplementary Table S7 and S8.

Table 4

Pooled partial correlations, Bayes Factors, and 95\% credibility intervals for associations between intelligence and vMMN latencies

\section{Scalp-Referenced}

\begin{tabular}{|c|c|c|c|c|c|c|}
\hline Statistic & $\mathrm{red} / 1^{\mathrm{st}}$ & green $/ 1^{\text {st }}$ & $\mathrm{red} / 2^{\text {nd }}$ & green $/ 2^{\text {nd }}$ & rule red & rule green \\
\hline Partial $r$ & 0.07 & -0.15 & 0.07 & -0.09 & 0.14 & $-0.29 *$ \\
\hline $\begin{array}{l}B F_{01} \\
C I\end{array}$ & $\begin{array}{l}5.17 \\
{[-.21, .33]}\end{array}$ & $\begin{array}{l}3.32 \\
{[-.36, .19]}\end{array}$ & $\begin{array}{l}5.15 \\
{[-.20, .31]}\end{array}$ & $\begin{array}{l}4.55 \\
{[-.36, .19]}\end{array}$ & $\begin{array}{l}3.45 \\
{[-.15, .41]}\end{array}$ & $\begin{array}{l}1.98 \\
{[-.47, .08]}\end{array}$ \\
\hline \multicolumn{7}{|c|}{ Laplacian-Transformed } \\
\hline Partial $r$ & 0.18 & 0.19 & 0.15 & 0.01 & 0.00 & -0.03 \\
\hline $\begin{array}{l}B F_{01} \\
C I\end{array}$ & $\begin{array}{l}2.59 \\
{[-.10, .43]}\end{array}$ & $\begin{array}{l}2.19 \\
{[-.08, .45]}\end{array}$ & $\begin{array}{l}3.33 \\
{[-.14, .41]}\end{array}$ & $\begin{array}{l}5.53 \\
{[-.25, .29]}\end{array}$ & $\begin{array}{l}5.67 \\
{[-.28, .28]}\end{array}$ & $\begin{array}{l}5.50 \\
{[-.29, .28]}\end{array}$ \\
\hline
\end{tabular}

Note: Partial $r=$ pooled partial correlation coefficients controlling for variance due to age and sex. Red $/ 1^{\text {st }}=$ ERP difference wave calculated from red deviants minus red standards from the first position in the stimulus pairs, $\mathrm{red} / 2^{\text {nd }}$, green $/ 1^{\text {st }}$, and green $/ 2^{\text {nd }}$ respectively. Correlations that reach significance in the imputed datasets are marked with an asterisk $\left(*=p<.05\right.$; uncorrected for six experimental conditions). Bayes Factors $\left(\mathrm{BF}_{01}\right)$ in favor of the null hypothesis (i.e., absence of correlation) and 95\% credibility Intervals (CI) are depicted for associations with RAPM scores.

\section{Post-Hoc Analysis: Neural Variability}

Finally, as an exploratory post-hoc analysis, we tested whether individual differences in intelligence are associated with the trial-to-trial variability of ERP amplitudes. Pearson partial correlations (controlled for variance due to age and sex) were computed for all twelve subconditions (epoch types) using the scalp-referenced data. As noted in the Methods section, these analyses focused on the standard error of the mean (SEM) obtained prior to calculating the primary ERPs. As shown in Supplementary Table 9, this analysis revealed no significant relationships between SEM amplitude variability in the ERPs and intelligence (all $p$-values $>$.326).

\section{Discussion}




\section{INTELLIGENCE AND VISUAL MISMATCH NEGATIVITY}

To the best of our knowledge, this is the first study to systematically test for a relation between intelligence and the MMN as an index of basic, pre-attentive automatic discrimination processes in the visual domain. Using a paradigm that has previously been shown to elicit a vMMN (Stefanics et al., 2011), we first aimed to replicate within-subject effects elicited by the experimental manipulation. Then, we tested for associations between individual differences in intelligence and vMMN amplitude and latencies. However, no significant effects were observed. Our results, therefore, question the association between general cognitive ability and neural indicators of automatic sensory discrimination processes in the visual modality.

The within-subject effects of stimulus position, perceptual deviance, and scalp location, in addition to violations of more abstract, rule-based expectations were examined first. For the more basic perceptual manipulation (simple condition), our results replicate previous findings for ERP amplitudes. Specifically, we observed a clear vMMN that was maximal near parietaloccipital, midline electrodes (Fig. 2), and larger (more negative) amplitudes in response to deviant and $2^{\text {nd }}$-position stimuli, relative to standard stimuli or those presented $1^{\text {st }}$ in a pair. Although the rule condition also elicited an ERP with the expected parieto-occipital topography, there were no amplitude effects related to stimulus deviance. Analyses of vMMN latencies revealed that, in the simple condition, neural activity peaked more rapidly in response to $2^{\text {nd }}$ versus $1^{\text {st }}$-position stimuli, and was also faster for deviants relative to standards. Also here, the spatial effects were centered near POz. For the rule condition, we observed a three-way interaction of Deviance, Anteriority, and Hemisphere where activity again peaked fastest near $\mathrm{POz}$, with the precise spatial pattern varying between the deviant and standard conditions.

In the individual differences analyses probing for relations between intelligence and vMMN amplitudes or latencies, we compared two different referencing schemes- the scalp-average reference and current source density via the Laplacian transform. For the scalp-referenced data, we relied on an a priori measurement window and set of electrodes, whereas, for the Laplaciantransformed data, measurement parameters were optimized to the current sample in a data-driven approach. As expected, the Laplacian transform revealed a more focal pattern of neural activity, which also peaked earlier than in the scalp-referenced data (based on the grand-average). Notwithstanding, both analyses approaches revealed no significant relationships between vMMN amplitudes and performance on the RAPM. Correlation analyses of vMMN latencies were likewise non-significant, with the sole exception of an inverse relation between vMMN latency in the rule condition (green stimuli, scalp-referenced data). Nevertheless, for both latencies and amplitudes, all credibility intervals contained zero, and Bayes Factors ranged from $\sim 2$ to 6 . As such, and taking into account the overall number of comparisons being investigated, we conclude that there is moderate to substantial evidence against a relationship between intelligence and vMMN amplitude or latencies in the present dataset.

The current findings contrast with studies reporting correlations between intelligence and the MMN in the auditory domain. Although results for individual studies are mixed, the overarching picture suggests larger MMN amplitudes (Sculthorpe et al., 2009; Troche et al., 2009, 2010), faster MMN latencies (e.g., Bazana \& Stelmack, 2002; Beauchamp \& Stelmack, 2006), or both (De Pascalis \& Varriale, 2012; De Pascalis et al., 2014; Houlihan \& Stelmack, 2012), in higher ability participants. One single study examined also the relation between intelligence and a version of the vMMN. That study, however, focused on socio-emotional rather than on automatic 

available under aCC-BY-ND 4.0 International license.

\section{INTELLIGENCE AND VISUAL MISMATCH NEGATIVITY}

perceptual processes. Specifically, the authors examined the vMMN in response to perceptually complex stimuli of neutral versus happy or sad facial expressions and observed larger MMN amplitudes in higher ability participants (Liu et al., 2015).

Plausible explanations for the discrepancy between the current results and previous studies include differences in measurement approaches (e.g., peak amplitudes and latencies vs. signed area amplitudes fractional area latencies), differences in specific task features, as well as broader considerations pertaining to different demands between the visual and auditory modalities. For example, although the current paradigm attempts to control participants' attention via the manipulation of fixation cross length, the effectiveness of this manipulation is somewhat unclear. In visual MMN paradigms both the attended and unattended stimuli are presented in the same modality. In contrast, in auditory MMN paradigms, participants' attention is most often kept by tasks in a different domain such as vision (e.g., by reading or watching a silent video). As vision is humans' dominant modality, efforts to control attentional might be more effective in this latter case. A related consideration concerns potential differences in the degree to which the two modalities may admit of individual differences in early perceptual processing. For example, it has been argued that auditory signals present an especially complex information processing challenge, due to their inherent transience, and the frequent need to distinguish multiple objects from within a single, multi-layered input (Fitzgerald \& Todd, 2020). Insofar as the two sensory modalities evolved to cope with different features of the environment, it is interesting to consider whether anatomical or physiological differences between early auditory and early visual pathways may affect the degree to which each admits of individual differences in their response properties. If so, this may in turn affect their potential for relations with intelligence. Similar considerations may also help to explain the discrepancy between our study that manipulated the colors and presented order of arrays of circles, versus that of Liu et al. (2015), which elicited the vMMN in response to emotional faces, i.e., to rather complex and highly socially-salient stimuli.

The present study also has several limitations which need to be considered. First, our sample size was comparatively small for analyses of individual differences in general (Yarkoni \& Braver, 2010; Gignac, \& Szodorai, 2016). Although our sample size was sufficient to detect medium to large effects (i.e., correlations > .35, see Methods) with $80 \%$ statistical power, we of course cannot exclude the possibility that we were simply unable to detect it. However, the present data-which tested associations for both amplitudes and latencies, across six ERP difference waves and two referencing schemes-suggests that any relationship, if it exists, is apt to be rather small, i.e., smaller as one would expect based on the previous literature on intelligence and auditory MMN. Replication studies using larger sample sizes are therefore essentially required. If those could confirm a null or very small association between basic pre-attentive visual processes and intelligence, this would be consistent with the hypothesis that correlations between intelligence and ERP features are expected to be smaller for less complex tasks and "lower-level" processes than for more complex "higher-level" cognitive functions (Euler \& Schubert, 2021; Euler, 2018). Thus, future studies that examine relations between intelligence and the vMMN would likely benefit from implementing a broader range of different task complexities. Respective studies could test for potential interactions between task complexity and stimulus modality and thus shed new light onto the conditions under which associations between vMMN and intelligence emerge. 


\section{INTELLIGENCE AND VISUAL MISMATCH NEGATIVITY}

A second limitation concerns the choice to examine correlations of intelligence with ERP difference waves, rather than their constituent ERPs. Several recent papers have re-focused attention on psychometric problems associated with using difference scores in individual differences research (e.g., Hedge et al., 2018), including in ERP studies per se (Meyer et al., 2020). Although this appears not to have hindered most auditory MMN studies, given the variable and often low correlations between the difference waves themselves in the current data (Supplementary Tables S5-S6), this is a worthwhile possibility to investigate in future research. Finally, it has also been recently argued that EEG and ERP studies may be more apt to observe relations with intelligence when all variables are modelled as latent factors, and at comparable levels of psychological and physiological aggregation (Euler \& Schubert, 2021; Schubert et al., 2017, 2021). While limitations of the present data preclude a more complex modelling approach along these lines, this represents another promising direction for future work.

In summary, this is, to the best of our knowledge, the first study testing for a relationship between intelligence and a basic perceptual manipulation of the MMN in the visual modality. Using a previously-validated paradigm, our results replicated prior experimental effects concerning the sensitivity of neural responses to deviant and second-position stimuli, albeit not to the violation of a more abstract, rule-based stimulus pattern. Most importantly, no associations between intelligence and vMMN amplitudes or latencies were observed, and Bayesian analyses indicated moderate to substantial evidence against any relationship. Future studies in this area will benefit from larger sample sizes, and by systematically exploring effects of task complexity and modality on relations between the MMN and intelligence.

\section{Acknowledgement}

The authors thank Prof. Dr. Christian Fiebach for supporting data acquisition and for helpful comments to a previous version of the manuscript.

\section{References}

Basten, U., Hilger, K., \& Fiebach, C. J. (2015). Where smart brains are different: A quantitative meta-analysis of functional and structural brain imaging studies on intelligence. Intelligence, 51, 10-27. https://doi.org/10.1016/j.intell.2015.04.009

Bazana, P. G., \& Stelmack, R. M. (2002). Intelligence and information processing during an auditory discrimination task with backward masking: An event-related potential analysis. Journal of Personality and Social Psychology, 83(4), 998-1008.

Beauchamp, C. M., \& Stelmack, R. M. (2006). The chronometry of mental ability: An eventrelated potential analysis of an auditory oddball discrimination task. Intelligence, 34(6), 571-586.

De Pascalis, V., Varriale, E., Fulco, M., \& Fracasso, F. (2014). Mental ability and information processing during discrimination of auditory motion patterns: Effects on P300 and mismatch negativity. Intelligence, 47, 93-106. shttps://doi.org/10.1016/j.intell.2014.09.006

De Pascalis, V., \& Varriale, V. (2012). Intelligence and information processing: A mismatch negativity analysis using a passive auditory backward-masking task. Journal of Individual Differences, 33(2), 101-108. https://doi.org/10.1027/1614-0001/a000078 

available under aCC-BY-ND 4.0 International license.

\section{INTELLIGENCE AND VISUAL MISMATCH NEGATIVITY}

Deary, I. J., Whiteman, M. C., Starr, J. M., Whalley, L. J., \& Fox, H. C. (2004). The impact of childhood intelligence on later life: following up the Scottish mental surveys of 1932 and 1947. Journal of personality and social psychology, 86(1), 130.

Delorme, A., \& Makeig, S. (2004). EEGLAB: an open source toolbox for analysis of single-trial EEG dynamics including independent component analysis. J Neurosci Methods, 134(1), 921.

Euler, M. J. (2018). Intelligence and uncertainty: Implications of hierarchical predictive processing for the neuroscience of cognitive ability. Neuroscience \& Biobehavioral Reviews, 94, 93-112.

Euler, M. J., \& Schubert, A. L. (2021). Recent developments, current challenges, and future directions in electrophysiological approaches to studying intelligence. Intelligence, 88 , 101569.

Euler, M. J., Weisend, M. P., Jung, R. E., Thoma, R. J., \& Yeo, R. A. (2015). Reliable activation to novel stimuli predicts higher fluid intelligence. NeuroImage, 114, 311-319. https://doi.org/10.1016/j.neuroimage.2015.03.078

Faul, F., Erdfelder, E., Lang, A. G., \& Buchner, A. (2007). G* Power 3: A flexible statistical power analysis program for the social, behavioral, and biomedical sciences. Behavior research methods, 39(2), 175-191.

Fitzgerald, K., \& Todd, J. (2020). Making sense of mismatch negativity. Frontiers in Psychiatry, 11, 468. https://www.frontiersin.org/articles/10.3389/fpsyt.2020.00468/full

Gignac, G. E., \& Szodorai, E. T. (2016). Effect size guidelines for individual differences researchers. Personality and individual differences, 102, 74-78.

Graham, J. W. (2009). Missing data analysis: Making it work in the real world. Annual review of psychology, 60, 549-576.

Gray, J. R., Chabris, C. F., \& Braver, T. S. (2003). Neural mechanisms of general fluid intelligence. Nat Neurosci, 6, 316-322.

Haier, R. J., White, N. S., \& Alkire, M. T. (2003). Individual differences in general intelligence correlate with brain function during nonreasoning tasks. Intelligence, 31, 429-441.

Haier, R. J., Jung, R. E., Yeo, R. A., Head, K., \& Alkire, M. T. (2004). Structural brain variation and general intelligence. Neuroimage, 23, 425-433.

Hedge, C., Powell, G., \& Sumner, P. (2018). The reliability paradox: Why robust cognitive tasks do not produce reliable individual differences. Behavior research methods, 50(3), 11661186.

Hilger, K., Winter, N. R., Leenings, R., Sassenhagen, J., Hahn, T., Basten, U., \& Fiebach, C. J. (2020a). Predicting intelligence from brain gray matter volume. Brain Structure and Function, 225(7), 2111-2129.

Hilger, K., Fukushima, M., Sporns, O., \& Fiebach, C. J. (2020b). Temporal stability of functional brain modules associated with human intelligence. Human Brain Mapping, 41(2), 362-372. https://doi.org/10.1002/hbm.24807

Hilger, K., \& Sporns, O. (2021). Network Neuroscience Methods in Studying Intelligence. In A. K. Barbey, S. Kamara, \& R. Haier (Eds.), The Cambridge Handbook of Intelligence and Cognitive Neuroscience. Cambridge University Press. https://doi.org/10.1017/9781108635462

Houlihan, M., \& Stelmack, R. M. (2012). Mental ability and mismatch negativity: Pre-attentive discrimination of abstract feature conjunctions in auditory sequences. Intelligence, 40(3), 239-244. https://doi.org/10.1016/j.intell.2012.02.003 

available under aCC-BY-ND 4.0 International license.

\section{INTELLIGENCE AND VISUAL MISMATCH NEGATIVITY}

Hutmacher, F. (2019). Why is there so much more research on vision than on any other sensory modality?. Frontiers in psychology, 2246.

Jeffreys, H. (1998). Theory of probability (3rd Ed.). OUP Oxford. https://doi.org/10.2307/3619118

Jung, R. E., \& Haier, R. J. (2007). The Parieto-Frontal Integration Theory (P-FIT) of intelligence: Converging neuroimaging evidence. Behavioral and Brain Sciences, 30(2), 135-187. https://doi.org/10.1017/S0140525X07001185

Kayser, J., \& Tenke, C. E. (2006). Principal components analysis of Laplacian waveforms as a generic method for identifying ERP generator patterns: I. Evaluation with auditory oddball tasks. Clinical Neurophysiology, $\quad$ 117(2), 348-368. https://doi.org/10.1016/j.clinph.2005.08.034

Kayser, J., \& Tenke, C. E. (2015). Issues and considerations for using the scalp surface Laplacian in EEG/ERP research: A tutorial review. International Journal of Psychophysiology, 97, 189-209.

Lipp, I., Benedek, M., Fink, A., Koschutnig, K., Reishofer, G., Bergner, S., Ischebeck, A., Ebner, F., \& Neubauer, A. (2012). Investigating neural efficiency in the visuo-spatial domain: an FMRI study. PLoS One, 7, e51316.

Liu, T., Xiao, T., Li, X., \& Shi, J. (2015). Fluid intelligence and automatic neural processes in facial expression perception: an event-related potential study. PLoS One, 10(9), e0138199.

Lopez-Calderon, J., \& Luck, S. J. (2014). ERPLAB: an open-source toolbox for the analysis of event-related potentials. Frontiers in Human Neuroscience, 8, 1-14. https://doi.org/10.3389/fnhum.2014.00213

Love, J., Selker, R., Marman, M., Jamil, T., Dropmann, D., Verhagen, J., ... Wagenmakers, E.-J. (2015). JASP: graphical statistical software for common statistical designs. Journal of Statistical Software.

Luck, S. J. (2014). An introduction to the event-related potential technique. MIT press.

Meyer, A., Lerner, M. D., De Los Reyes, A., Laird, R. D., \& Hajcak, G. (2017). Considering ERP difference scores as individual difference measures: Issues with subtraction and alternative approaches. Psychophysiology, 54(1), 114-122.

Näätänen, R., Paavilainen, P., Rinne, T., \& Alho, K. (2007). The mismatch negativity (MMN) in basic research of central auditory processing: A review. Clinical Neurophysiology, 118(12), 2544-2590. https://doi.org/10.1016/j.clinph.2007.04.026

Nathan, M. J., \& Del Pinal, G. (2017). The Future of Cognitive Neuroscience? Reverse Inference in Focus. Philosophy Compass, 12(7), e12427. https://doi.org/10.1111/phc3.12427

Neisser, U., Boodoo, G., Bouchard Jr, T. J., Boykin, A. W., Brody, N., Ceci, S. J., ... \& Urbina, S. (1996). Intelligence: knowns and unknowns. American psychologist, 51(2), 77.

Pazo-Alvarez, P., Cadaveira, F., \& Amenedo, E. (2003). MMN in the visual modality: a review. Biological psychology, 63(3), 199-236.

Poldrack, R. A. (2008). The role of fMRI in cognitive neuroscience: Where do we stand? $\begin{array}{llll}\text { Current Opinion in } \quad \text { Neurobiology, } & \text { 223-227. }\end{array}$ https://doi.org/10.1016/j.conb.2008.07.006

Poldrack, R. A. (2011). Inferring mental states from neuroimaging data: From reverse inference to large-scale decoding. Neuron, 72(5), 692-697. https://doi.org/10.1016/j.neuron.2011.11.001 
bioRxiv preprint doi: https://doi.org/10.1101/2022.03.01.482097; this version posted March 3, 2022. The copyright holder for this preprint (which was not certified by peer review) is the author/funder, who has granted bioRxiv a license to display the preprint in perpetuity. It is made available under aCC-BY-ND 4.0 International license.

\section{INTELLIGENCE AND VISUAL MISMATCH NEGATIVITY}

Poldrack, R. A. (2015). Is "efficiency" a useful concept in cognitive neuroscience? Developmental Cognitive Neuroscience, $11, \quad 12-17$. https://doi.org/10.1016/j.dcn.2014.06.001

Raven, J. C., \& Court, J. H. (1998). Raven's progressive matrices and vocabulary scales. Oxford Psychologists Press.

Schafer, J. L., \& Graham, J. W. (2002). Missing Data: Our View of the State of the Art. Psycnet. Apa. Org, 7(2), 147-177. https://doi.org/10.1037/1082-989X.7.2.147

Schmidt, F. L., \& Hunter, J. (2004). General mental ability in the world of work: occupational attainment and job performance. Journal of personality and social psychology, 86(1), 162.

Schubert, A.-L., Hagemann, D., \& Frischkorn, G. T. (2017). Is general intelligence little more than the speed of higher-order processing? Journal of Experimental Psychology: General, 146(10), 1498-1512. https://doi.org/10.1037/xge0000325

Schubert, A. L., Hagemann, D., Löffler, C., Rummel, J., \& Arnau, S. (2021). A chronometric model of the relationship between frontal midline theta functional connectivity and human intelligence. Journal of Experimental Psychology: General, 150(1), 1.

Sculthorpe, L. D., Stelmack, R. M., \& Campbell, K. B. (2009). Mental ability and the effect of pattern violation discrimination on P300 and mismatch negativity. Intelligence, 37(4), 405411. https://doi.org/10.1016/j.intell.2009.03.006

Sinharay, Stern, \& Russell, 2001. The use of multiple imputation for the analysis of missing data. Psychological Methods, 6(4), 317-329

Stefanics, G., Kimura, M., \& Czigler, I. (2011). Visual Mismatch Negativity Reveals Automatic Detection of Sequential Regularity Violation. Frontiers in Human Neuroscience, 5(46), 1-9. https://doi.org/10.3389/fnhum.2011.00046

Stefanics, G., Kremláček, J., \& Czigler, I. (2014). Visual mismatch negativity: a predictive coding view. Frontiers in Human Neuroscience, 8(666), 1-19. https://doi.org/10.3389/fnhum.2014.00666

Troche, S. J., Houlihan, M. E., Stelmack, R. M., \& Rammsayer, T. H. (2009). Mental ability, P300, and mismatch negativity: Analysis of frequency and duration discrimination. Intelligence, 37(4), 365-373. https://doi.org/10.1016/j.intell.2009.03.002

Troche, S. J., Houlihan, M. E., Stelmack, R. M., \& Rammsayer, T. H. (2010). Mental ability and the discrimination of auditory frequency and duration change without focused attention: An analysis of mismatch negativity. Personality and Individual Differences, 49(3), 228-233. https://doi.org/10.1016/j.paid.2010.03.040

Wagenmakers, E. J. (2007). A practical solution to the pervasive problems of $\mathrm{p}$ values. Psychonomic Bulletin and Review, 14, 779-804. https://doi.org/10.3758/BF03194105

Wetzels, R., \& Wagenmakers, E. J. (2012). A default Bayesian hypothesis test for correlations and partial correlations. Psychonomic Bulletin and Review, 19(6), 1057-1064. https://doi.org/10.3758/s13423-012-0295-X

Yarkoni, T., \& Braver, T. S. (2010). Cognitive neuroscience approaches to individual differences in working memory and executive control: conceptual and methodological issues. In Handbook of individual differences in cognition (pp. 87-107). Springer, New York, NY. 


\section{simple conditions}

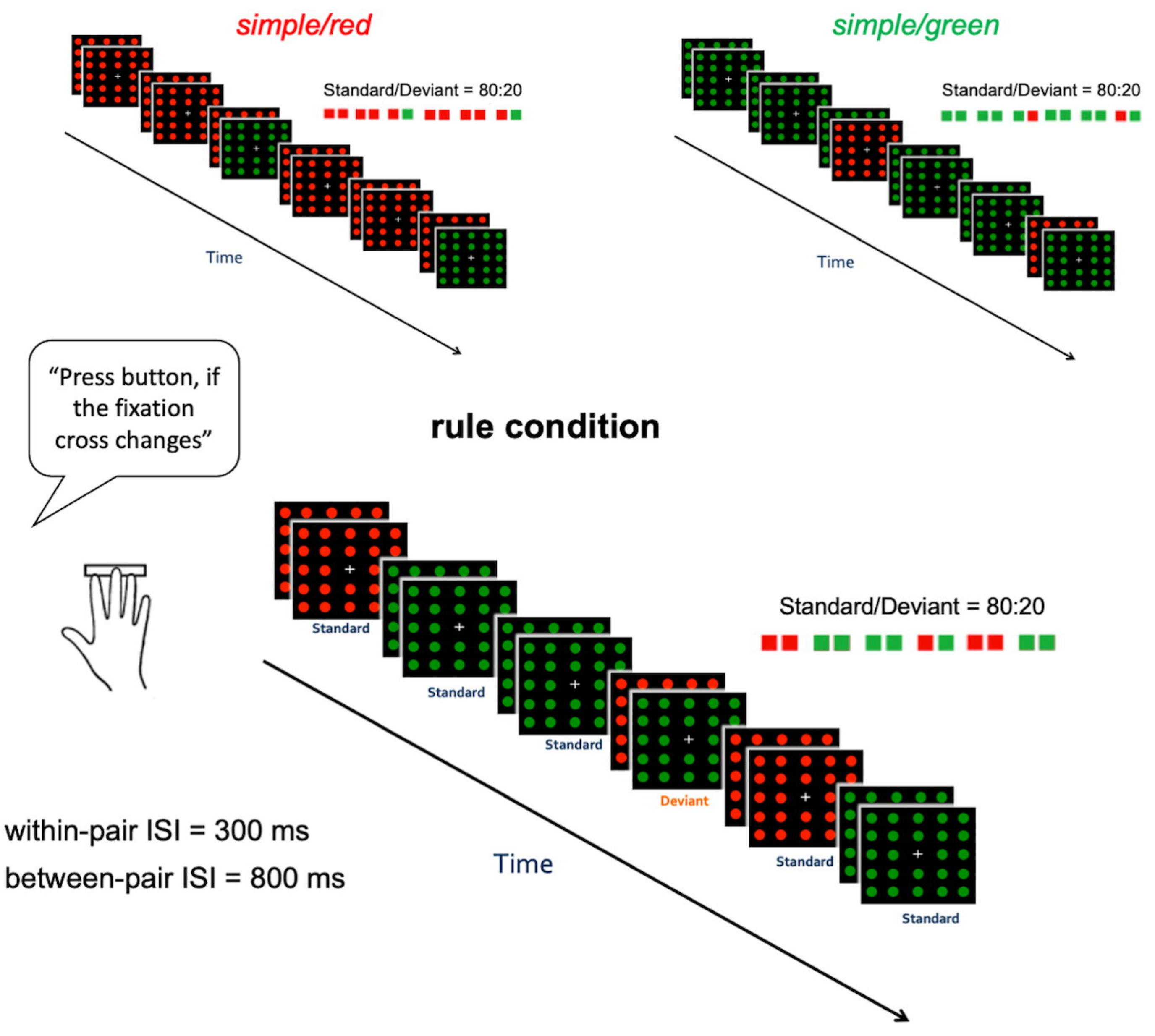



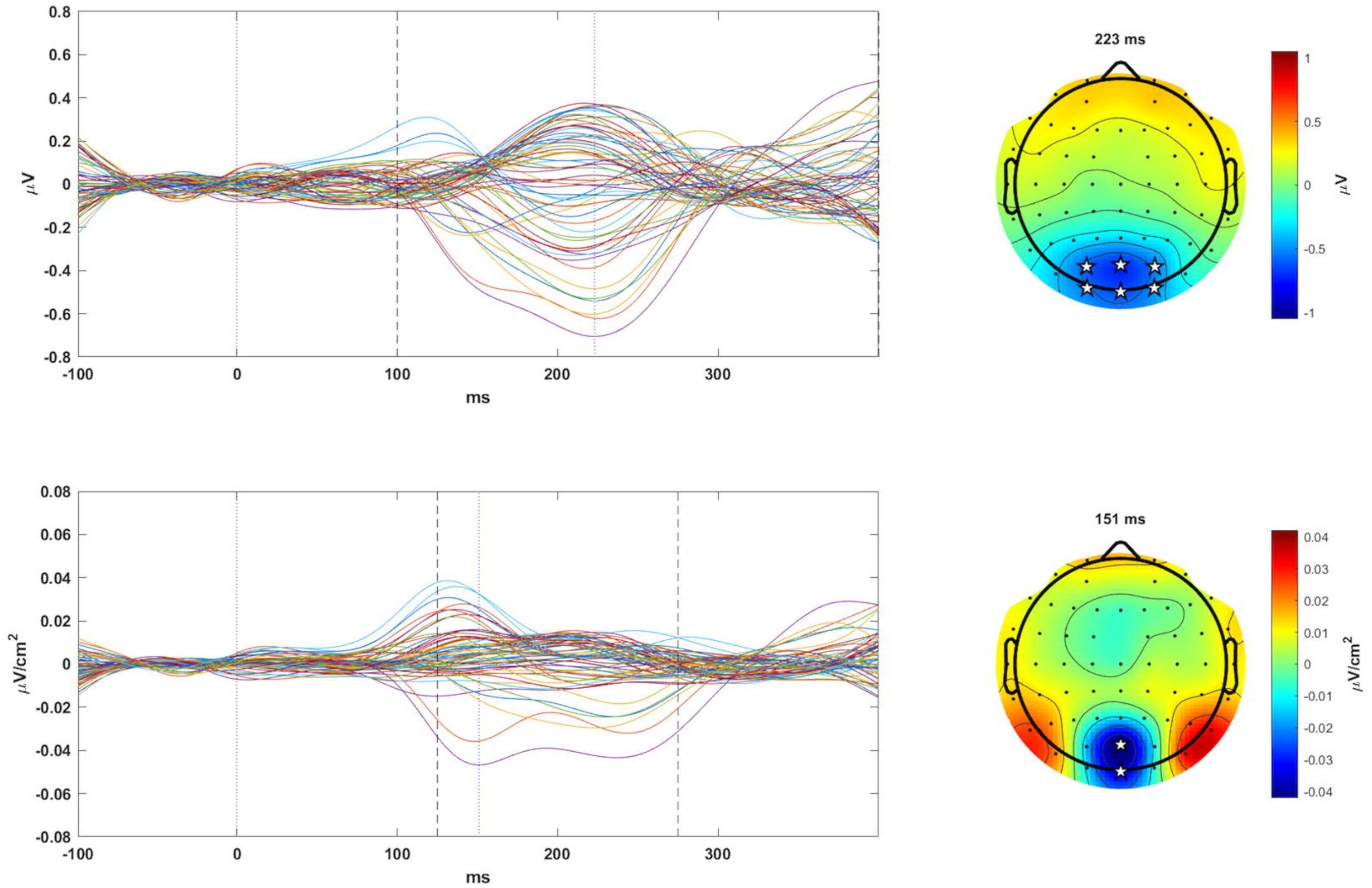